\title{
Propostas de produção de gêneros do meio digital em livro didático de língua inglesa
}

\section{Proposals for the production of digital genres in English language textbooks}

\author{
Karolinne Finamor Couto'; Vera Lúcia Lopes Cristovão
}

\begin{abstract}
Resumo
Pretendemos, neste artigo, discutir os resultados do recorte de uma pesquisa de mestrado cujo objetivo foi o de investigar se as propostas de produção de gêneros do meio digital em livros didáticos de língua inglesa contribuem para o desenvolvimento dos letramentos. Nossas discussões teóricas são baseadas na concepção de gênero (BAKHTIN, 2000; BRONCKART, 2009; MARCUSCHI, 2004), letramento (BRASIL, 2006; ROJO, 2009) e nas orientações dos Parâmetros Curriculares Nacionais (BRASIL, 1998). Nosso corpus - composto por atividades de produção escrita presentes em uma coleção aprovada pelo PNLD/2011, Keep in Mind (CHIN; ZAORAB, 2009) - foi analisado em interface com os critérios de avaliação do Edital e do Guia, a fim de que pudéssemos responder as perguntas de pesquisa. Nossos resultados mostram que os critérios do edital e do guia são coerentes, no entanto, as propostas de produção não desenvolvem eficazmente os letramentos, sobretudo, por não oferecerem práticas reais de comunicação em suporte digital, incluídas aí as etapas do processo de produção escrita: planejamento, escrita e reescrita de gêneros.
\end{abstract}

Palavras-chaves: Livro didático. Gêneros do meio digital. Letramentos.

\section{Summary}

We intend, in this article, to discuss the results of a part of a Master research whose objective was to investigate whether the proposals for the production of digital genres in English language textbooks contribute to the development of literacies. Our theoretical discussions are based on the concept of genre (BAKHTIN, 2000; BRONCKART, 2009; MARCUSCHI, 2004), literacy (BRASIL, 2006; ROJO, 2009) and the guidelines of the National Curriculum Parameters (BRASIL, 1998). Our corpus - consisting of written production activities present in a didactic collection approved by PNLD/2011, Keep in Mind (CHIN; ZAORAB, 2009) - was analyzed in interface with the Guide and Announcement criteria, so that we could answer the research questions. Our results show that the criteria of the Announcement and the Guide are consistent, however, the proposals for written production do not effectively develop literacies, especially for not offering real communication practices in digital format, including therein the steps of the written production process: planning, writing and rewriting.

Keywords: Textbook. Digital genres. Literacies.

\footnotetext{
${ }^{1}$ Mestre em Letras pela Universidade Federal da Grande Dourados (UFGD) e aluna de Doutorado no Programa de Pós-Graduação em Linguística e Língua Portuguesa da UNESP. E-mail: karolinnecouto@gmail.com.

${ }^{2}$ Doutora em Linguística Aplicada e Estudos da Linguagem pela Pontifícia Universidade Católica de São Paulo. Professora Associada do Departamento de Letras Estrangeiras Modernas da Universidade Estadual de Londrina. E-mail: veraluciacristovao@gmail. com
} 


\section{Introdução}

O livro didático (LD) foi, histórica e socialmente, constituído como um dos principais documentos inseridos no cenário educacional. Ele compõe-se como uma modalidade de material didático cuja função tem sido nortear a sequência de conteúdos a serem trabalhados em sala de aula. Isso tem acontecido principalmente na disciplina de língua inglesa, na qual, na maioria das vezes, o LD é a única fonte de textos, atividades e conteúdos extras que o professor utiliza para programar as aulas. A ideia de que o material sempre apresentará um programa adequado para cada etapa escolar é algo que está no imaginário coletivo das instituições educacionais. Este fator leva professores, demais profissionais da escola e alunos a consagrarem o uso do material e atribuir a ele segurança suficiente ao ponto de concluirmos que ele é, de fato, aceito como o principal guia que rege os programas curriculares ao longo dos bimestres. Tal consagração do LD foi a principal motivação que nos levou a tê-lo como objeto a ser investigado, não somente com enfoque específico na produção de gêneros, mas os processos sociais nos quais ele está inserido (história, avaliação, distribuição).

Ao longo dos anos, o LD foi configurado de formas diferentes, trazendo em si os reflexos sociais, políticos, culturais das épocas, reproduzindo discursos vigentes e fazendo emergir ideologias capazes de construir imaginários coletivos e disseminar práticas sociais que caracterizariam toda uma geração. As mudanças ocorridas na sociedade trouxeram, inevitavelmente, novas configurações das práticas sociais e, assim, novas linguagens exigiram que não somente a escola, mas todos os recursos didáticos fossem, também, transformados, a fim de serem condizentes e suficientes para atender às novas gerações.
Portanto, é fato que, num mundo cada vez mais marcado por novas práticas de linguagem, a instituição escolar, os professores, os recursos didáticos, dentre eles o próprio $\mathrm{LD}$, inseriram essas novas linguagens como conteúdos e formas ${ }^{3}$ a serem ensinados/aprendidos de maneira a contribuir para a formação de alunos, capacitando-os, como sujeitos ativos, posicionados, letrados e prontos para exercer sua cidadania nos mais diversos contextos sociais.

Dentre essas novas práticas de linguagem, as quais podem ser chamadas de novos letramentos, estão inseridas as práticas digitais. A comunicação online, bem como todos os gêneros emergentes dela, são hoje realidade marcante na vida não somente dos alunos, mas da sociedade como um todo. Assim sendo, por meio deste texto, pretendemos discutir os resultados de um recorte de uma pesquisa de mestrado realizada entre 2011 e 2013, por meio da qual, nos debruçamos sobre as propostas de produção de gêneros do meio digital (GMD), presentes em duas coleções de livros didáticos de língua inglesa. Tal pretensão nos levou a unir duas realidades diferentes, principalmente no aspecto histórico: de um lado, o LD como um material secular; e, de outro, os GMD, como uma prática de linguagem dos novos tempos. Na dissertação, focamos em duas coleções (as mais adotadas no município de Dourados/MS, local de realização da pesquisa); no entanto, trataremos apenas de uma das coleções neste artigo: Keep in Mind do Ensino Fundamental.

A partir dos documentos oficiais do Ministério da Educação (MEC) (BRASIL, 1998, 2006, 2008, 2010) e fundamentados em teóricos dos estudos sobre letramento (KLEIMAN, 1995; ROJO, 2009; ROJO; MOURA, 2012) e estudo sobre gêneros (BRONCKART, 2009; MARCUSCHI, 2002, 2005; SCHNEUWLY; DOLZ, 2004), pretendemos, na

\footnotetext{
${ }^{3}$ Não basta incluir o ensino de novas práticas de linguagem, mas repensar a maneira pela qual se ensina e se aprende os elementos constitutivos dos gêneros textuais, incluindo os aspectos linguísticos, os quais constituem as capacidades discursivas e linguísticodiscursivas de linguagem.
} 
pesquisa de mestrado, investigar se as propostas de produção dos GMD no livro didático favoreciam o desenvolvimento dos letramentos. Neste artigo, em especial, o recorte se deu em torno de algumas reflexões acerca da coleção da coleção Keep in Mind, aprovada pelo PNLD/2011. Antes de prosseguir, é importante salientar que, sendo, a circulação dos GMD, uma realidade contemporânea e emergente, é pertinente, sem dúvida, o desenvolvimento de pesquisas em torno desse tema, não só pelo aumento da prática dessas novas ou reformuladas linguagens, mas, sobretudo, pela necessidade de se repensar os papéis da escola, enquanto instituição responsável por centrar no engajamento discursivo do aprendiz (BRASIL, 1998). Além das funções da escola, mais especificamente o ensino de língua estrangeira, é de substancial importância que seja feita a discussão em torno das ferramentas de ensino/aprendizagem, no nosso caso, o LD.

Este artigo traz, a seguir, algumas considerações teóricas e metodológicas do trabalho, e, por último, as conclusões da análise de duas propostas de atividades presentes na coleção, sendo uma do $8^{\circ}$ ano-e-mail, e outra do $9^{\circ}$ ano - mensagem em site.

\section{Aspectos Teóricos e Metodológicos}

\section{Os gêneros textuais}

Uma vez que esta pesquisa se propõe a estudar os GMD presentes no LD, faz-se de suma importância apresentar o que estamos entendendo por gênero neste contexto. Para isso, nos apoiamos no Interacionismo Sociodiscursivo (ISD), corrente teórica de cunho psicológico 4 iniciada por um grupo de pesquisadores da Universidade de Genebra, tendo, como principal precursor, Jean-Paul Bronckart. De acordo com Bronckart (2009), este quadro busca analisar as condutas humanas como ações cujas estruturas são fruto da própria socialização, e, dentre tais condutas, estão situadas as verbais, que sempre se apresentam em interdependência com ações não verbais.

Apoiado na visão interacionista vygotskyniana dos processos sociais (VYGOTSKI, 2007, 2008) e na filosofia bakhtiniana linguagem (BAKHTIN, 2000) o ISD inclina os seus pressupostos para o estudo da linguagem, mais especificamente, o estudo do ensino/aprendizagem de línguas. Estudar a linguagem, nesta vertente, vai além da elaboração de modelos para produção de textos, trata-se de uma busca para entender as produções verbais como ações contextualizadas e que, uma vez ligadas a esses contextos, resultar-se-ão nos GMD (GONÇALVES, 2011).

Ao defender que as atividades humanas são construídas em um processo histórico e social mediado por símbolos, principalmente pela linguagem (CRISTOVÃO, 2008), o ISD tem se apoiado numa visão interacionista de linguagem. Neste sentido, "a linguagem humana se apresenta, inicialmente, como uma produção interativa associada às atividades sociais, sendo ela o instrumento pelo qual os interactantes, intencionalmente, emitem pretensões à validade relativa às propriedades do meio em que essa atividade se desenvolve" (BRONCKART, 2009, p. 34).

A linguagem, portanto, apresenta-se como constitutivamente interativa entre sujeitos em suas

${ }^{4} \mathrm{O}$ ISD, devido às suas raízes, é considerado um construto de cunho psicológico, pois amplia os pressupostos elaborados por Vygotsky que confrontava seriamente a noção epistemológica dualista herdada de Descartes (que influenciou grandemente todo um modo de fazer ciência). Vygotsky sustentava um conceito unificador, era adepto da epistemologia Monista (metafísica monista formulada por Spinoza) que considerava a natureza ou o universo constituído de uma substância única, formada por múltiplas propriedades, dentre elas, o físico e o psíquico. Estes últimos, por sua vez, são as únicas propriedades acessíveis à inteligência humana que, possuindo propriedades limitadas, "não pode apreender a matéria de que se origina como uma entidade homogênea ou contínua, mas sob forma parcial e descontínua dos fenômenos físicos e psíquicos” (BRONCKART, 2009, p. 26). 
variadas organizações sociais, fruto de interações linguísticas e resultam no que chamamos de gêneros. Bakhtin (2000) denomina gêneros do discurso como tipos relativamente estáveis de enunciados; possuem uma natureza histórica, sociointeracional, ideológica e linguística; são engendrados a partir das esferas sociais permeadas pela utilização da língua, ou seja, segundo o autor, por meio desses enunciados (gêneros), é que a língua é efetuada e organizada. Os gêneros se desenvolvem, ao passo que as atividades humanas se desenvolvem e se complexificam, em outras palavras: a quantidade de gêneros torna-se infinita, já que o ser humano, como ator social, não cessa suas atividades. É por isso que a língua não é concebida separada da sociedade, mas atuante sobre e movida por ela.

Ao observar os pressupostos do ISD, a noção de texto, segundo Bronckart (2009, p. 71), “designa toda unidade de produção de linguagem que veicula uma mensagem linguisticamente organizada e que tende a produzir um efeito de coerência sobre o destinatário". O autor situa o texto como uma entidade genérica que apresenta as seguintes características:

- Cada texto está em relação de interdependência com as propriedades do contexto em que é produzido;

- Cada texto exibe um modo determinado de organização de seu conteúdo referencial;

- Cada texto é composto de frases articuladas uma às outras, de acordo com regras de composição mais ou menos estritas;

- [...] Cada texto apresenta mecanismos de textualização e mecanismos enunciativos destinados a lhe assegurar coerência interna. (BRONCKART, 2009, p. 71).

Observamos, portanto, que o texto, nesta abordagem teórico-metodológica, é a unidade que permite o aprendizado de múltiplas habilidades, uma vez que é uma entidade diretamente ligada aos seus contextos de produção, aos usos reais da linguagem, ou seja, a uma perspectiva externa. Além disso, tal perspectiva apresenta-se como dependente de mecanismos internos de cunho estrutural, termos estrategicamente escolhidos para que o sentido seja produzido e que o objetivo final da produção seja alcançado. Assim, o gênero pode "ser considerado um megainstrumento que fornece um suporte para a atividade, nas situações de comunicação, e uma referência para os aprendizes" (SCHNEUWLY; DOLZ, 2004, p. 64).

Ao ser concebido como objeto de ensino, o gênero passa de uma prática comunicativa de referência (circulação na sociedade) a um conteúdo a ser aprendido pelos alunos (objeto de ensino). Com isso, acontece a transposição didática, processo no qual "há um desdobramento que se opera em que o gênero não é mais instrumento de comunicação somente, mas é, ao mesmo tempo, objeto de ensinoaprendizagem" (SCHNEUWLY; DOLZ, 2004, p. 65).

A transposição didática deve ser feita de maneira a desenvolver o que Schneuwly e Dolz (2004) chamam de capacidades de linguagem: capacidades mobilizadas durante as atividades de compreensão e produção textual e que são divididas em três tipos: 1) Capacidades de ação: constitui a primeira fase da ação de leitura ou produção textual. As capacidades de ação mobilizam informações a respeito do contexto de produção do gênero: lugar e momento de produção, quem são os sujeitos envolvidos, o que escreve e para quem escreve, os objetivos da comunicação; 2) capacidades discursivas: são referentes ao plano geral do gênero, o tipo de discurso e o tipo de sequência; 3) capacidades linguístico-discursivas: são referentes aos mecanismos de textualização (coesão verbal e coesão nominal), mobiliza o reconhecimento das unidades linguísticas a serviço da compreensão e da produção do texto.

No movimento do gênero, das práticas comunicativas reais para a sala de aula como objeto de ensino, segundo Schneuwly e Dolz (2004), três aspectos podem caracterizar a atividade de ensino. Nas nossas análises dos dados, buscamos identificar 
as características que os gêneros assumem, ao passar da prática de referência para objeto de ensino: 1) desaparecimento da comunicação: a comunicação desaparece, e o gênero torna-se uma pura forma linguística, expressão do pensamento, não há relação entre o gênero e a situação de comunicação; 2) a escola como lugar de comunicação: este aspecto é identificado, quando a escola é concebida como o lugar autêntico de produção e circulação do gênero, os alunos são expostos a situações onde a escrita se torna possível, os gêneros são produzidos naturalmente, nascem das situações e, portanto, não são ensinados; e 3) negação da escola como lugar específico de comunicação: ao contrário do tipo anterior, neste, o gênero é focado exclusivamente como funciona nas práticas de referência, ele é concebido na escola tal como exteriormente a ela. Nesta abordagem, não se pensa a escrita como um processo, o objetivo se volta totalmente para o domínio do gênero nas práticas reais (SCHNEUWLY; DOLZ, 2004).

Os estudiosos de Genebra elencam, então, os pontos fortes e fracos das três abordagens:

Quadro 1 - Pontos fortes e fracos das três maneiras de abordar o gênero

\begin{tabular}{|c|c|c|}
\hline & Pontos fortes & Pontos fracos \\
\hline $\begin{array}{l}\text { Desaparecimento da } \\
\text { comunicação }\end{array}$ & $\begin{array}{l}\text { - necessidade de criaçóes de } \\
\text { objetos escolares para um } \\
\text { ensino-aprendizagem eficaz } \\
\text { - pensamento em progressão }\end{array}$ & $\begin{array}{l}\text { - progressåo como processolinear, } \\
\text { do simples para o complex o, } \\
\text { definido por meio do objeto } \\
\text { descrito } \\
\text { - Abordagem puramente } \\
\text { representacional, } \\
\text { comunicativa }\end{array}$ \\
\hline $\begin{array}{l}\text { A escola como lugar de } \\
\text { comunicação }\end{array}$ & $\begin{array}{l}\text { - Leva muito em conta a } \\
\text { particularidade das situações } \\
\text { escolares e sua utilização } \\
\text { - Importância do sentido da escrita } \\
\text { - Tônica na autonomia dos } \\
\text { processos de aprendizagem } \\
\text { nessas situações }\end{array}$ & $\begin{array}{l}\text { - Năo leva em conta modalos } \\
\text { externos, explicitamente, e não } \\
\text { os utiliza } \\
\text { - Não modelização das formas de } \\
\text { linguagem e, portanto, ausência } \\
\text { de ensino }\end{array}$ \\
\hline $\begin{array}{c}\text { Negação da escola como } \\
\text { lugar específico de } \\
\text { comunicação }\end{array}$ & $\begin{array}{l}\text { - Evidencia as contribuiçóes das } \\
\text { práticas de referência } \\
\text { - Importância do sentido da escrita } \\
\text { - Insistência na dimensão } \\
\text { comunicativa e na variedade das } \\
\text { situações }\end{array}$ & $\begin{array}{l}\text { - Negação da particularidade das } \\
\text { situações escolares como lugares } \\
\text { de comunicação que } \\
\text { transformam as práticas de } \\
\text { referência } \\
\text { - Ausência de reflexão sobre a } \\
\text { progres sãoe o desenvolvimento }\end{array}$ \\
\hline
\end{tabular}

Fonte: Schneuwly e Dolz (2004, p. 68).

O ensino da língua, que leva em consideração a produção dos gêneros, pode tanto fomentar no discente o posicionamento discursivo como contribuir para que este desenvolva o caráter composicional da linguagem. Este fator, portanto, colabora para que os aprendizes possam ter uma formação voltada para o engajamento social e para o reconhecimento dos múltiplos discursos que permeiam na sociedade. Sendo assim, considerando a linguagem o principal veículo pelo qual se realizam os processos criadores e transformadores em uma sociedade, o ISD não visa ao trabalho com a língua, enquanto um fenômeno utilizado para a expressão de pensamentos ou um sistema fechado 
de códigos, mas ao trabalho com a linguagem, enquanto prática social, conforme ela se apresenta e ocorre no mundo.

\section{Os gêneros do meio digital}

Em um mundo cada vez mais mediado pela Internet, as relações sociais têm sofrido mutações, e muitas maneiras de interação humana, antes, só possíveis presencialmente, hoje, podem acontecer via Web. Como consequência, as práticas de linguagem, também, passaram a se configurar de novas maneiras, ou seja, a interação dos sujeitos, por meio da Internet, resultou nos gêneros do meio digital. E-mails, chats, blogs, formulários eletrônicos, entre outros, são gêneros cada vez mais comuns na comunicação virtual cotidiana. O e-mail, por exemplo, é um dos gêneros mais utilizados no mundo moderno ${ }^{5}$, sendo praticado para a troca de mensagens de natureza diversa, ocupando ou dividindo o lugar com a tradicional carta. Os chats (bate-papo) permitem conversas instantâneas com um ou mais interlocutores, por meio de produção escrita e oral, além de disponibilizarem a opção da comunicação via webcam. Os blogs, utilizados para disponibilizar conteúdos escritos, orais, imagéticos, audiovisuais, facilitam a ligação para outras páginas, por meio de links. O formulário eletrônico, utilizado para que o internauta forneça informações necessárias para se integrar em comunidades virtuais, registrar-se em sites de compras e redes sociais, inscrever-se em eventos, dentre outras funções. Enfim, os GMD incorporam novas formas de apresentação da linguagem e propiciam a dinamização das interações. Marcuschi (2005) nos lembra que muitos desses gêneros não são exatamente novos, mas como projeções de outros já existentes. Deste modo, os chats se configuram como as rodas de conversas face a face e assim por diante.

Embora cada gênero apresente suas características constitutivas, é fato que a grande marca dos digitais é a multimodalidade, essa interrelação entre linguagem verbal, sons, imagens que é substancial na construção dos sentidos. Assim, uma imagem ou um som não são apenas peças ilustrativas de um texto escrito, mas parte necessária para que a comunicação seja estabelecida (BRASIL, 2006). Esse fator sugere, ao enfocar no trabalho com letramento, que os pensamentos se voltem para os vários modos de disposição da informação. Segundo Dionísio (2005), no mundo atual, “à prática de letramento da escrita, do signo verbal, deve ser incorporada a prática de letramento da imagem, do signo visual" (DIONÍSIO, 2005, p. 160), é, por isso, justamente que o termo letramentos (no plural) torna-se mais adequado, ao lidar com o letramento por meio dos GMD. A autora afirma, ainda, que tanto textos escritos como orais são multimodais, pois, ao falarmos ou escrevermos, estamos utilizando mais de um modo de representação, no caso de gêneros orais, palavras e gestos ou palavras e entonações; no caso dos escritos, palavras e imagens, palavras e tipográficas. (DIONÍSIO, 2005).

O trabalho com a produção do GMD, fonte inesgotável de multimodalidade, permite o desenvolvimento dos letramentos, ${ }^{6}$ pois possibilita a compreensão e a produção textual, por meio de várias formas de representação da linguagem, constituindo-se para os alunos uma atividade de ordem complexa, justamente pelo desafio de ter que construir sentidos a partir de um conjunto diversificado de representações.

\footnotetext{
${ }^{5}$ Estamos entendendo o e-mail como gênero, ao aproximá-lo da carta. Nesse caso, ocorre uma assimilação de um gênero por outro. Nas palavras de Marcuschi (2002), que relembram Bakhtin (1997), ocorre a transmutação do gênero. Assim, concebe-se o e-mail como sucessor da carta, é nesse sentido que o consideramos gênero. Mas o e-mail, também, pode exercer outra função, quando enviamos uma receita culinária, um arquivo de áudio, uma piada, dentre outros gêneros, seja em anexo ou no corpo do e-mail, este deixa de ser um gênero e passa a ser suporte para outros gêneros.

${ }^{6}$ Trata-se de "um conjunto muito diversificado de práticas sociais situadas que envolvem sistemas de signos, como a escrita ou outras modalidades de linguagem, para gerar sentidos" (ROJO, 2009, p. 10).
} 


\section{Procedimentos metodológicos}

Nossa pesquisa se situa na área da Linguística Aplicada, de natureza qualitativa, seguindo o paradigma interpretativista. $\mathrm{Na}$ vertente interpretativista, o pesquisador busca um compromisso com as interpretações das ações e com os sentidos que os sujeitos atribuem a elas (BORTONI-RICARDO, 2008). Segundo esta abordagem, "não há como observar o mundo independentemente das práticas sociais e significados vigentes. [...] a capacidade de compreensão do observador está enraizada em seus próprios significados, pois ele (ou ela) não é um relator passivo, mas um agente ativo" (BORTONIRICARDO, 2008, p. 32). Sendo assim, a figura do pesquisador torna-se influente na interpretação dos dados, pois ele está situado em determinada época e espaço cujas características ficam evidentes em suas ações.

Em relação ao método de coleta de dados, esta pesquisa se utiliza de procedimentos de análise documental, a partir da qual, pretendemos buscar informações nos documentos, a partir das questões propostas para esta investigação.
Segundo Lüdke e André (1986, p. 38), a análise documental "pode se constituir numa técnica valiosa de abordagem de dados qualitativos, seja complementando as informações obtidas por outras técnicas, seja desvelando aspectos novos de um tema ou problema". No caso da nossa pesquisa, a análise documental foi o único procedimento de coleta de dados, realizada nos livros didáticos, nos documentos do PNLD e nos PCN.

Para a análise de dados, sintetizamos, a seguir, as categorias que foram geradas a partir dos próprios documentos inseridos no processo de avaliação das coleções (o Edital de Convocação das Editoras e o Guia de Livros Didáticos). Nosso objetivo não foi o de estabelecer novos aspectos a serem observados no LD, mas utilizar os critérios já existentes, tanto no Edital de convocação das obras, quanto no Guia de Livros Didáticos. Dessa forma, as categorias utilizadas para analisar as atividades emergiram de um diálogo que constatamos entre o Edital e o Guia. Ambos os grupos de critérios presentes nos dois documentos mostraram considerável coerência entre si, permitindo-nos elencar, a partir deles, os tópicos norteadores da nossa análise.

Quadro 2 - Categorias de análise para as propostas do Ensino Fundamental

\begin{tabular}{|c|c|c|c|}
\hline \multicolumn{4}{|c|}{ Categorias de análise do Ensino Fundamental } \\
\hline Categoria de análise 1 & Categoria de análise 2 & Categoria de análise 3 & Categoria de análise 4 \\
\hline $\begin{array}{l}\text { A coleçāo propōe } 0 \\
\text { desenvolvimento da escrita } \\
\text { de gêneros diversificados? }\end{array}$ & $\begin{array}{l}\text { As capacidades de açāo, ou } \\
\text { seja, o contexto de } \\
\text { produçào entendido aqui } \\
\text { como "o conjunto dos } \\
\text { parámetros que podem } \\
\text { exercer uma influência } \\
\text { sobre a forma como o texto } \\
\text { é organizado". sào } \\
\text { desenvolvidas na coleçâo? }\end{array}$ & $\begin{array}{l}\text { As capacidades linguistico- } \\
\text { discursivas sầ } \\
\text { desenvolvidas nas } \\
\text { atividades de escrita, por } \\
\text { meio do emprego de } \\
\text { mecanismos do sistema } \\
\text { linguistico adequados ao } \\
\text { contexto de produçào? }\end{array}$ & $\begin{array}{l}\text { A proposta de produção } \\
\text { escrita desenvolve as } \\
\text { etapas de produçăo: } \\
\text { planejamento, escrita e } \\
\text { reescrita? }\end{array}$ \\
\hline
\end{tabular}

Fonte: Brasil (2008). 
Devido ao recorte de nossa pesquisa para este artigo, centraremos nossas discussões apenas nas categorias 2, 3 e 4. Na seção seguinte, apresentamos nossas conclusões.

\section{Análise: Um Olhar Para os GMD}

Neste tópico, objetivamos responder à indagação proposta. Esta resposta abrange a observância de algumas propostas de produção de GMD presentes na coleção Keep in Mind (CHIN; ZAORAB, 2009a, 2009b). Verificamos se as propostas estão de acordo com o que defendem os critérios do Edital e do Guia (categorias de análise), e concluir se as atividades contribuem ou não para desenvolver os letramentos do aluno.

\section{A coleção keep in mind}

Neste artigo, apresentamos as análises de duas ocorrências, uma do volume do $8^{\circ}$ ano (CHIN; ZAORAB, 2009a) (gênero e-mail), e uma do volume do $9^{\circ}$ ano (CHIN; ZAORAB, 2009b) (gênero mensagem em site), com base nas categorias de análise 2, 3 e 4. Para cada análise, fizemos a descrição da proposta de escrita, apresentando juntamente uma imagem da página onde ela está disponibilizada. Após a descrição, pretendemos responder às questões de pesquisa, apresentada por meio das categorias de análise.

\section{$8^{\circ}$ Ano-e-mail}

O volume do $8^{\circ}$ ano (CHIN; ZAORAB 2009a). apresenta atividades de escrita que envolvem o gênero e-mail em três unidades, das quais, apresentamos a unidade 12, disposta nas páginas 138 e 139. Esta atividade não está ligada à outra seção (leitura, oralidade, compreensão), e traça caminhos para que o estudante escreva um e-mail, em resposta ao outro mostrado no exercício. A atividade é dividida em três partes. Na primeira parte (figura 1), é apresentado um e-mail enviado por um emissor chamado Pedro (emissor), supostamente colega de sala do aluno (destinatário), estabelecendo uma comunicação hipotética. Na mensagem, o emissor fala da ausência do destinatário na aula daquele dia, passa um aviso de uma atividade a ser realizada e um lembrete sobre um jogo de basquete. O objetivo é que este e-mail sirva como um contexto no qual o aprendiz deva intervir posteriormente, respondendo-o.

Figura 1 - Proposta de produção escrita do gênero e-mail - primeira parte.

\section{Act 9 Let's write Professorlak: Leia o o-mair de Padro com os alunos a pargunto-has por que Podro o escreveu}

(1) Read this e-mail from Pedro to you.

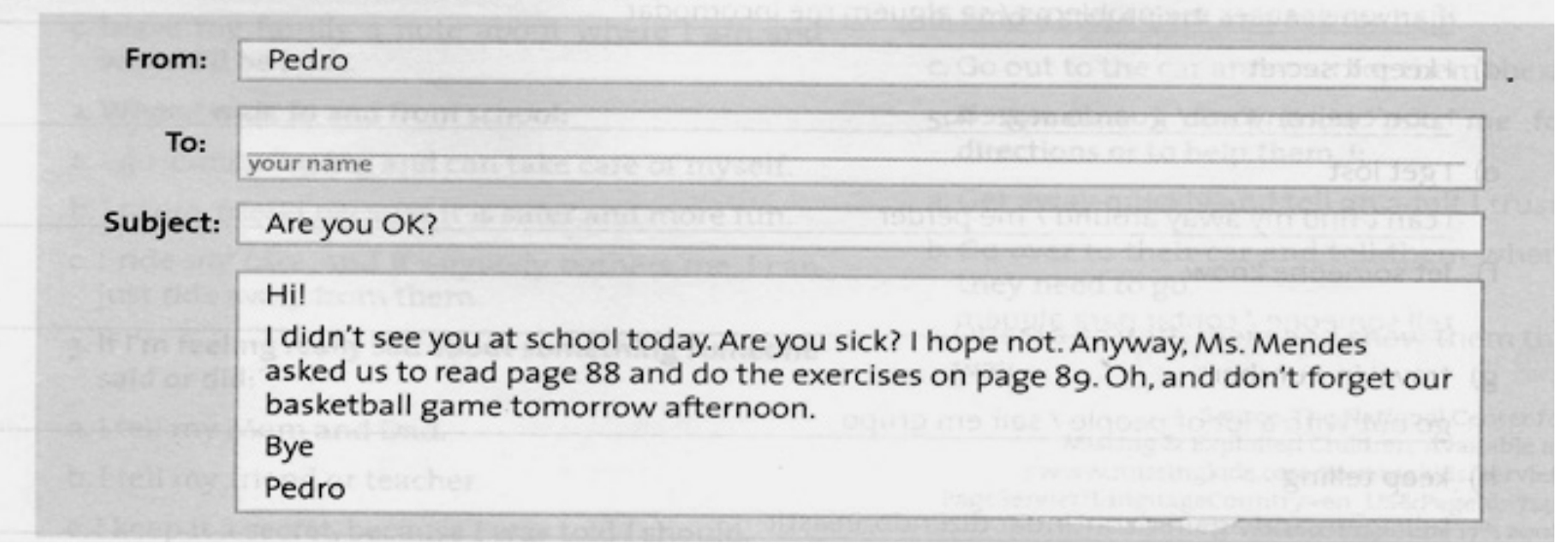

Fonte: Chin e Zaorab (2009a). 
$\mathrm{Na}$ segunda parte (figura 2), o exercício orienta o aluno para que organize as ideias em preparação à resposta do e-mail. Para isso, o aluno deve preencher quatro tópicos, informações que serão utilizadas na resposta ao Pedro: por que eu faltei; o que eu fiz; como me sinto agora; o que eu vou fazer. Como se trata de uma situação imaginária, o estudante precisará inventar as informações para escrever, desde que sejam coerentes com o contexto imposto pelo LD. O objetivo desta segunda parte, provavelmente, foi a de proporcionar ao aluno uma etapa de pré-escrita do gênero, maneira de controlar a estrutura do texto e o conteúdo, isto é: uma atividade de organização textual para encaminhar a produção posterior. É necessário ressaltar, também, que os quatro tópicos a serem respondidos, nesta segunda parte, são uma chave para que o aluno se instrumentalize com o vocabulário e a gramática aprendidos nas seções anteriores da lição.

Figura 2 - Proposta de produção escrita do gênero e-mail - segunda parte

\section{Organize your ideas to write a reply.}

\section{Why I was absent Personal answers.}

\section{What I did}

\section{How I feel now}

\section{What I'm going to do}

Fonte: Chin e Zaorab (2009a).

$\mathrm{Na}$ terceira parte (figura 3), o aluno é convidado a escrever a resposta ao Pedro, com base nos apontamentos da parte 2 do exercício. Há quatro campos a serem preenchidos: remetente, destinatário, assunto do texto e o texto. A atividade deverá ser feita no próprio livro, ou seja, fora do ambiente digital, o que leva a visualizá-lo mais como um questionário onde as respostas estão na primeira parte da lição (vocabulário e gramática), do que a produção de um e-mail em si.
Figura 3 - Proposta de produção escrita do e-mail - terceira parte

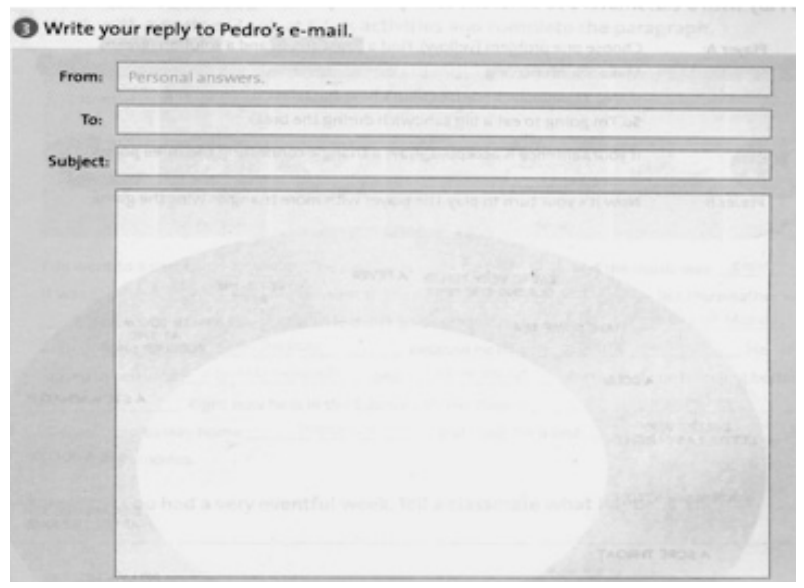

Fonte: Chin e Zaorab (2009a). 
Descrita a atividade, passaremos a abordar as três perguntas propostas para esta análise.

Categoria de análise 2: As capacidades de ação, ou seja, o contexto de produção entendido aqui como o conjunto dos parâmetros, que podem exercer uma influência sobre a forma de organização do texto, são desenvolvidas na coleção?

O comando de escrita fornecido ao aluno declara que ele deverá produzir um e-mail em resposta ao Pedro, isto é, o modelo presente na primeira parte do exercício serve como gênero de referência e, também, como uma provocação, razão para que o aprendiz estabeleça comunicação pelo texto a ser produzido. Isso é posto no LD, pelo fato de que a aprendizagem acontece a partir da clareza de todo o processo de escrita, levando em conta os objetivos da comunicação (BRASIL, 1998). No entanto, não há reflexão a respeito do gênero: estrutura do texto, elementos da página online (campos a serem preenchidos) ou ferramentas multimodais. Para o LD, nesta atividade, o que importa são as informações que o aluno apresentará, são as respostas dos tópicos da segunda parte, em que o aluno poderá utilizar o conteúdo aprendido nas seções de vocabulário e gramática. Acresce-se isso ao fato de que é um GMD produzido fora do suporte digital. Podemos dizer que, com exceção de haver um destinatário (Pedro), ainda que imaginário, para se estabelecer a comunicação, o exercício não proporciona informações relevantes ao contexto de produção. Os PCN (BRASIL, 1998), ao tecerem considerações sobre o processo de produção escrita, evidenciam que um dos principais desafios dessa competência é lidar com a "ausência do interlocutor", impedindo a simultaneidade na comunicação (diferente da oralidade, por exemplo), levando o aprendiz a projetar o interlocutor reportado. Podemos observar, no entanto, que alguns dos GMD permitem o estabelecimento da comunicação com outro sujeito de maneira simultânea, aproximando a prática de linguagem da oralidade, mas, por meio da escrita. No caso do e-mail, a comunicação pode ser síncrona ou assíncrona, porém, a realização da escrita do e-mail fora do ambiente digital é uma condição que anula qualquer possibilidade de interação síncrona real.

Categoria de análise 3: As capacidades linguístico-discursivas são desenvolvidas nas atividades de escrita, por meio do emprego de mecanismos do sistema linguístico adequados ao contexto de produção?

Na maneira pela qual foi apresentada, a proposta de produção favorece que o aluno utilize os mecanismos gramaticais (tempos verbais: passado, presente e futuro) e de vocabulário (partes do corpo, doenças e soluções) supostamente aprendidos nas seções anteriores da lição. Sendo assim, podemos dizer que é uma atividade totalmente a serviço desse conteúdo, ao permitir que o aluno pratique os tópicos aprendidos, mas sem levar em conta a complexidade da produção de um gênero e a reflexão em torno dos mecanismos do sistema lingüístico, em relação estreita com o gênero, bem como sua função social.

Categoria de análise 4: A proposta de produção escrita desenvolve as etapas de produção: planejamento, escrita e reescrita?

A atividade é dividida em três partes; na primeira, busca dar o contexto de produção ao aluno e fornecer um gênero de referência; a segunda oferece ao aluno a possibilidade de organizar as informações a serem apresentadas no e-mail de resposta; e a terceira fase é a escrita propriamente dita. No que diz respeito ao planejamento do texto, houve uma tentativa, por parte do LD, de realizá-la por meio da segunda parte da atividade. Esse planejamento é feito em tópicos aos quais o aluno deve responder, a fim de gerar informações que comporão o conteúdo do texto a ser produzido.

A terceira etapa do exercício constitui a escrita do gênero. $\mathrm{O}$ espaço disponível para a escrita na página do livro imita timidamente uma página online com quatro campos a serem preenchidos: remetente, destinatário, assunto e corpo do texto. Apesar disso, o aluno é privado de muitas outras propriedades, características e particularidades intrínsecas ao 
e-mail, como o desenvolvimento da linguagem multimodal, a possibilidade de anexar arquivos em diversos formatos, a assinatura eletrônica e inserção de links.

Não há orientação, no livro do aluno, para que o processo de escrita passe por revisão e possível reescrita, tampouco nas orientações do MP. Concordamos, portanto, com a ideia de que a proposta de produção do gênero e-mail desenvolve um tipo de planejamento da escrita (parte 2) baseada no elenco de informações cujo conteúdo constituirá o novo texto. $O$ ensino não parte da premissa do desenvolvimento de um GMD, mas de uma atividade tradicional de escrita, na própria página do LD, e não há evidências para a possível reescrita do texto.

Em relação à atividade do $8^{\circ}$ ano, vamos apresentar algumas observações em torno das características que observamos ter essa proposta, no que diz respeito à transposição didática do gênero e-mail das práticas reais de comunicação para o material didático, como objeto a ser ensinado e aprendido. Foram constatadas, nesse exercício, duas características: a escola como lugar de comunicação e o desaparecimento da comunicação. O primeiro item foi observado a partir da ideia de que, nessa proposta, a escola é concebida como lugar autêntico de comunicação, isto é, os alunos são expostos a situações, em que a produção se torna possível, trata-se da naturalização da escrita. Neste caso, tal gênero não é, assim, tratado como tal, não é descrito, nem menos ainda, prescrito, nem tematizado como forma de aprendizagem (SCHNEUWLY; DOLZ, 2004). Tal proposta leva em conta as situações escolares e propõe certa autonomia ao escritor, por outro lado, não concebe importância aos modelos externos, bem como não promove modelização do gênero, o que significa, segundo os autores, que não ocorre ensino.

No caso do desaparecimento da comunicação, esta foi observada, principalmente, na segunda parte da atividade, quando o aluno é convidado a organizar as ideias para escrever, posteriormente, a resposta ao e-mail. Esta organização de ideias é feita com base em quatro critérios: 1. Why I was absent; 2. What I did; 3. How I feel now; 4. What I'm going to do. Observando atentamente, constatamos que tais tópicos levarão o aluno a produzir períodos no passado, no presente e no futuro, os três tempos verbais que são o foco da seção gramatical da unidade. Há, portanto, por parte do LD, uma tendência de propor ao aluno a reprodução dos aspectos gramaticais, para confirmar se o aluno aprendeu a produzir frases nos três tempos verbais, conforme orientou a seção estrutural da lição. O desaparecimento da comunicação ocorre, simplesmente, pelo fato de que a atividade não tem propósito comunicativo, mas sim um foco gramatical.

\section{$9^{\circ}$ Ano - mensagem em site de aconselhamento}

Dentre os GMD trabalhados no livro do $9^{\circ}$ ano (CHIN; ZAORAB, 2009b), está disponível, na página 129, um exercício cujo objetivo é ensinar os alunos a pedir e a dar conselhos num site próprio para isso. Assim, o LD apresenta aos alunos um site real (www.kidzworld.com), com pretensão de proporcionar-lhes o entendimento sobre como funciona esse processo comunicativo de pedir e dar conselhos no universo adolescente.

A atividade é dividida em três partes. A primeira apresenta ao aluno o serviço online de aconselhamento, no qual deve ler o texto exposto e descobrir o que é Dear Dish-It. A novidade da proposta é que ela trabalha com um site, realmente, existente na web, possibilitando, ao aluno, acessálo e praticar a produção do gênero, posteriormente, para fins pessoais.

O texto que os alunos devem ler na primeira parte do exercício traz a introdução/apresentação do Dear Dish-It, um serviço disponível no site www. kidzworld.com cujo objetivo é dar conselhos para ajudar a esclarecer dúvidas e a resolver problemas do público-alvo. As temáticas são sempre voltadas 
para essa faixa etária, tais como bullying, depressão e relacionamentos. Basta que o jovem internauta envie seu pedido de conselho e será respondido pelo serviço Dear Dish-It.

Figura 4 - Proposta de produção escrita do gênero mensagem em site - primeira parte

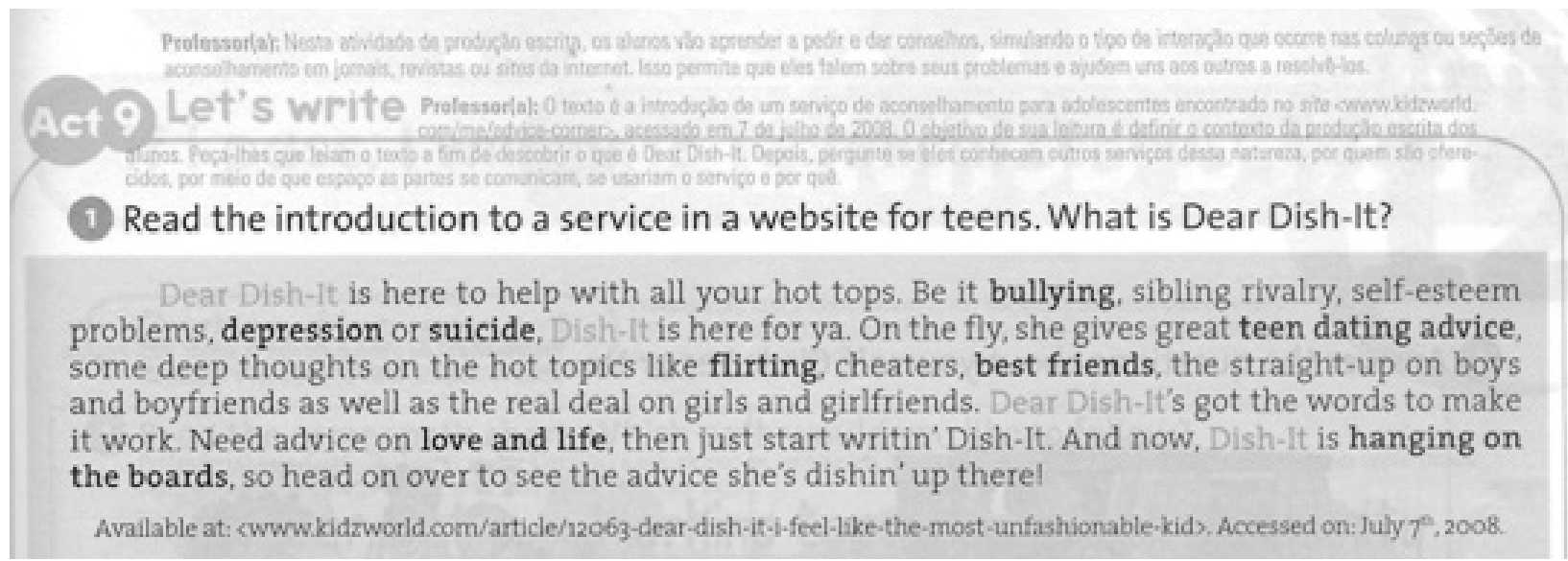

Fonte: Chin e Zaorab (2009a).

A segunda parte da atividade (figura 5) apresenta um exemplo desta prática comunicativa retirada da própria página do site. Em seguida, é solicitado ao aluno ler o modelo e discutir alguns pontos com a turma. Tais pontos indicam o que é crucial na produção desse gênero (o problema do internauta, o conselho disponibilizado pelo site) a ser produzido, posteriormente, por ele.

Figura 5 - Proposta de produção escrita do gênero mensagem em site - segunda parte

\section{Read a request for advice and the reply from Dear Dish-It. Discuss with your class.}

a) What is the problem? Is it clearly stated? Can we tell how Anonymous feels?

b) What is the advice? Do you think it is good? Why or why not?

c) Why does the person asking for advice sign as Anonymous? is this usual?

d) How does Dear Dish-It show empathy towards Anonymous?

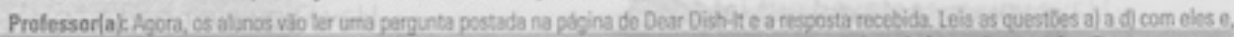

Dear Dish-It

Hey! I have a little problem... I feel like I'm THE MOST unfashionable kid on earth. I really want some nice clothes that I can wear to school without being embarrassed. I'm always wearing the same clothes over and over again day by day and week by week (...) Please reply!

\section{Anonymous}

Dear Anonymous,

I hear ya. No one wants to wear the same clothes day in and day out - but you can wear your everyday pieces in different ways and make it seem like your wardrobe is a lot bigger than it actually is! For example, you can wear your jeans the plain and regular way one day, fold them at mid-calf to turn 'em into capris another day, and accessorize it with a big belt or wide sash yet another day (...)

Available at: $\langle$ www.kidzworld.com/article/12063-dear-dish-it-i-feel-like-the-most-unfashionable-kid $\rangle$. Accessed on: July $7^{\text {th }}, 2008$.

Fonte: Chin e Zaorab (2009a). 
A terceira parte da atividade (figura 6) propõe a produção do gênero pelo aluno. As orientações prescrevem uma série de ações a serem realizadas coletiva e individualmente. A princípio, a classe deverá criar um serviço de aconselhamento e lhe atribuir um nome. Em seguida, cada aluno deverá escrever um pedido de conselho e disponibilizá-lo para a sala. Pede-se o uso de pseudônimo. Depois de disponibilizadas as mensagens, cada aluno vai ler a do colega, respondê-la e disponibilizar novamente. Assim, cumpre-se o objetivo geral da proposta: pedir conselho e aconselhar. Ainda, como conclusão da atividade, após ler a resposta do colega sobre a sua indagação, o aluno deverá observar se o conselho dado ajudou ou não no seu problema/dúvida inicial.

Figura 6 - Proposta de produção escrita do gênero mensagem em site - terceira parte

\section{Write, read and reply.}

a) Create an advice service in and for your class. Discuss and decide what it will be called.

b) Write a question or a request for advice. You can sign it with a pen name.

c) Post your question or request in the classroom. Read your classmates' writings.

d) Choose one question or request to reply to. Then, post it next to the original text.

e) Read the reply to your question or request. Did it help?

Fonte: Chin e Zaorab (2009a).

Novamente, temos um GMD orientado para ser produzido fora do ambiente digital. Além disso, não percebemos indicação de possibilidade de trabalho com o gênero, nem pelo meio real digital nem mediante orientações para os professores. Apesar de, desta vez, o LD não pecar na apresentação do gênero de referência, orienta a execução da atividade de maneira tradicional: papel e caneta, assemelhando-se a um correio escolar.

Dado o olhar geral da proposta, podemos discutila a partir das categorias de análise.

Categoria de análise 2: As capacidades de ação, ou seja, o contexto de produção entendido aqui como o conjunto dos parâmetros, que podem exercer uma influência sobre a forma de organização do texto, são desenvolvidas na coleção?

Em relação ao contexto de produção, os alunos são bem situados, pois, a partir do gênero de referência, um site real, são levados a construir o seu próprio ambiente de comunicação: um serviço de aconselhamento. Nesse processo, ocorrem dois desvios: um é o fato de ser um GMD produzido fora do meio digital; o outro é que, enquanto na prática de referência, o interlocutor é o administrador do site, no gênero a ser produzido, o interlocutor são os próprios colegas. O primeiro é prejudicial, já que descaracteriza o gênero, transformando-o em um correio escolar. O segundo, também, anula uma das características dessa prática digital, na qual, há um interlocutor que não é conhecido, definido apenas como "quem opera o site", pode ser um psicólogo especialista em adolescentes, pode ser uma pessoa ou um grupo dedicado a isso. Por outro lado, a mudança do interlocutor, no momento de produzir o gênero, vai permitir que os alunos desenvolvam as duas práticas discursivas: pedir conselho e aconselhar, enquanto, na prática real, ele só desenvolveria a primeira ação.

Categoria de análise 3: As capacidades linguístico-discursivas são desenvolvidas nas 
atividades de escrita, por meio do emprego de mecanismos do sistema linguístico adequados ao contexto de produção?

A terceira parte do exercício, momento em que o aluno vai produzir o texto, não aponta orientação quanto ao emprego de mecanismos do sistema linguístico. $\mathrm{O}$ gênero mensagem de aconselhamento é coerente com o tema central da lição, ao retratar problemas e características comuns na fase da adolescência: relacionamentos, brigas, vida escolar, entre outros. Apesar disso, o tópico gramatical da lição, o tempo verbal Present Perfect, não aparece no gênero de referência, fazendo-nos notar que o foco da atividade é o desenvolvimento do vocabulário temático da lição e não necessariamente os mecanismos gramaticais.

Categoria de análise 4: A proposta de produção escrita desenvolve as etapas de produção: planejamento, escrita e reescrita?

Não podemos considerar, necessariamente, a etapa 2 uma etapa de planejamento do texto, mas uma etapa que visa a levar o aluno a refletir sobre a prática de referência, pensando na sua escrita. Nessa fase, o aluno deveria ler o gênero de referência e discutir com os colegas algumas perguntas. Essas perguntas o levam a identificar e refletir a respeito dos pontos essenciais do conteúdo do texto: o problema do adolescente, o conselho recebido pelo site, se é um bom conselho ou não, o motivo pelo qual o internauta "identificou-se" como anônimo, a maneira pela qual o interlocutor demonstrou empatia para com o jovem. Em outras palavras, tratam-se de tópicos que ajudarão o aprendiz a organizar os seus escritos, tanto ao pedir conselho quanto ao aconselhar.

A escrita é feita fora da web, dando, à prática comunicativa, outra função. O aluno se reportará a outro colega, o interlocutor é diferente do qual seria numa situação real de comunicação. A orientação é a de que os aprendizes escrevam uma pergunta ou um pedido de conselho e coloquemse à disposição da turma; pode-se escrever, além disso, um pseudônimo intencionando conservar a identificação. A atividade só é completada, quando cada participante escolhe um pedido de conselho para atender. Invertem-se os papéis, os aprendizes, primeiramente, são o "adolescente internauta" que pergunta; em seguida, "o serviço do site" que responde com aconselhamentos.

A atividade permite, portanto, que o aluno ocupe dois papéis sociais. Tal característica dá à proposta um caráter complexo, fazendo com que a turma, num exercício coletivo, realize por completa a prática comunicativa. Além de o texto de todos chegarem a um destino (o colega que vai responder), voltará às mãos de quem produziu, permitindo que este emita algum parecer sobre o conselho recebido, se foi bom, se ajudou ou não. Poderíamos afirmar que o gênero circula, estabelecendo a completude da situação de comunicação: pedir conselho $->$ dar conselho -> receber conselho -> avaliar o conselho.

Apesar de haver circulação real do gênero entre os interlocutores, não há qualquer indicação, por parte do LD, para a possível reescrita do texto. A última etapa da atividade, quando os alunos recebem o conselho pedido, seria uma boa oportunidade para que, além de avaliarem se o conselho ajudou ou não, fossem discutidas outras características da escrita: a estrutura composicional, o conteúdo temático do texto, os mecanismos linguísticos. Seria uma abertura para que os próprios alunos fizessem a correção da atividade e, coletivamente, melhorassem as produções.

Finalizando a análise da proposta do $\mathrm{LD}-9^{\circ}$ ano, comentaremos a respeito das duas características constatadas nessa proposta. Na primeira parte da atividade, observamos a negação da escola como lugar de comunicação. Trata-se de uma prática real de referência externa do gênero a ser aprendido, ou seja, há subsídios para que o aluno tenha acesso a essa prática linguística e fornecimento de condições para visualizar e reconhecer o gênero tal qual ele funciona fora da escola. Este fato faz com que a proposta vise à dimensão comunicativa da escrita, 
a fim de que ela possa significar algo para os sujeitos em processo de aprendizagem. O objetivo é dominar o gênero, exatamente, como no mundo real; porém, percebemos a ausência de reflexão sobre a progressão e o desenvolvimento da escrita, o que tira da escola o caráter de "lugar particular de ensino-aprendizagem".

Já, nas segunda e terceira partes da atividade, percebemos sinais da escola como lugar de comunicação. No momento em que o aluno é convidado a produzir de fato o gênero, depara-se com uma atividade fora do ambiente virtual que simula os pedidos e fornecimentos de conselho. $\mathrm{O}$ aluno é situado em um contexto em que a escrita ocorre como ação mecânica, automática, natural, a partir dos comandos recebidos. Apesar da ideia reproduzir o gênero de referência, este é deixado em segundo plano, transformado em uma dinâmica de grupo fora do ambiente virtual, ou seja, descaracteriza o gênero. A comunicação fica restrita ao ambiente escolar, torna-se natural, promove o ensino das formas de linguagem (pedir e dar conselho); porém, não como GMD, apenas como prática escrita com as quais, provavelmente, o aluno nunca se deparará, ao decorrer das suas experiências de letramento.

\section{Considerações Finais}

No recorte de nossa pesquisa, apresentamos análise de duas propostas presentes na coleção Keep in Mind do Ensino Fundamental, gênero e-mail e mensagem para site. Concluímos que as atividades dos LD buscam desenvolver a escrita, mas não como prática de letramento, tampouco têm potencial para o trabalho multimodal. O trabalho com o contexto de produção foi limitado nas duas ocorrências, e as tentativas ocorridas foram sufocadas por outros complicadores. As propostas não fomentam a produção do GMD em plataforma digital, um grande agravante que anula a possibilidade de desenvolver o gênero, explorando uma de suas principais características: a multimodalidade. As atividades não propuseram a etapa de reescrita do texto, deixando claro que o aprendizado da escrita não é o foco da proposta. Pudemos constatar que a seção de produção de texto da unidade tem servido como exercício de fixação do vocabulário ou gramática. Das características elencadas por Schneuwly e Dolz (2004), a respeito do movimento do gênero das práticas de referência para objeto de ensino, foram constadas as três: desaparecimento da comunicação, escola como lugar de comunicação e negação da escola como lugar de comunicação.

As propostas analisadas fazem parte de uma coleção aprovada pelo primeiro PNLD de LEM. O nosso objetivo foi buscar entender como este fenômeno vem acontecendo e abrir espaço para que seja fonte de maiores discussões que ultrapassem as barreiras do LD. Isso significa que, para entender os aspectos específicos do LD, é importante levarmos em conta fatores externos a ele, principalmente, o fato de que a disciplina de LI, ainda, não tem uma identidade estruturada no cenário educacional, por fatores tais como as deficiências na formação dos professores e a mínima carga horária no currículo. Enfim, todos esses aspectos agravantes podem prejudicar a formação de uma identidade para a disciplina, o que resulta, também, em problemas na hora de autores de LD pensarem a sua elaboração. Soma-se a isso o fato de que, como supracitado, este PNLD foi o primeiro, o que, provavelmente, tem gerado, por parte da academia, uma série de discussões que poderão contribuir para a melhoria do material nos PNLD posteriores.

\section{Referências}

BAKHTIN, M. Estética da criação verbal. São Paulo: Martins fontes, 2000.

BORTONI-RICARDO, S. M. O professor pesquisador: introdução à pesquisa qualitativa. São Paulo: Parábola editorial, 2008. 
BRASIL. Ministério da Educação. Secretaria de Educação Básica. Edital de convocação para inscrição no processo de avaliação e seleção de obras didáticas para o Programa Nacional do Livro Didático PNLD 2011: ensino fundamental. Brasília, 2008.

- Guia de livros didáticos PNLD 2011: língua estrangeira moderna: ensino fundamental. Brasília, 2010.

- Orientações curriculares para ensino médio. Brasília, 2006.

. Parâmetros curriculares nacionais língua estrangeira. Brasília, 1998.

BRONCKART, J. P. Atividade de linguagem, textos e discursos: por um interacionismo sociodiscursivo. São Paulo: EDUC, 2009.

CHIN, E. Y.; ZAORAB, M. L. Keep in mind: ensino fundamental: $8^{\circ}$ ano. São Paulo: Scipione, 2009a.

. Keep in mind: ensino fundamental: $9^{\circ}$ ano. São Paulo: Scipione, 2009b.

CRISTOVÃO, V. L. L. Interacionismo sociodiscursivo (ISD): quadro teóricoepistemológico para estudos da linguagem. In: . (Org.). Estudos da linguagem à luz do interacionismo sociodiscursivo. Londrina: EDUEL, 2008 .

DIONÍSIO, Â. P. Gêneros multimodais e multiletramentos. In: KARWOSKI, A. M.; GAYDECZKA, B.; BRITO, K. S. (Org.). Gêneros textuais: reflexões e ensino. Palmas: Kaygangue, 2005. p. 135-151.

GONÇALVES, A.V. Gêneros textuais na escola: da compreensão à produção. Dourados: EDUFGD, 2011.

LÜDKE, M.; ANDRÉ, M. Pesquisa em educação: abordagens qualitativas. São Paulo: EPU, 1986.
MARCUSCHI,L.A. Gêneros textuais: configuração, dinamicidade e circulação. In: KARWOSKI, A. M.; GAYDECZKA, B.; BRITO, K. S. (Org.). Gêneros textuais: reflexões e ensino. Palmas: Kaygangue, 2005. p. 23-36.

Gêneros textuais: definição e funcionalidade. In: DIONÍSIO, Â. P.; MACHADO, A. R.; BEZERRA, M. A. (Org.). Gêneros textuais \& ensino. Rio de Janeiro: Lucerna, 2002. p. 19-36. Gêneros textuais emergentes no contexto da tecnologia digital. In: MARCUSCHI, L. A.; XAVIER, A. C. (Org.). Hipertexto e gêneros digitais. Rio de Janeiro: Lucerna, 2004. p. 13-67.

ROJO, R. Letramentos múltiplos, escola e inclusão social. São Paulo: Parábola, 2009.

ROJO, R.; MOURA, E. (Org.). Multiletramentos na escola. São Paulo: Parábola, 2012.

SCHNEUWLY, B.; DOLZ, J. Gêneros orais e escritos na escola. Campinas: Mercado de Letras, 2004.

VYGOTSKI, L. S. A formação social da mente. São Paulo: Martins Fontes, 2007. Pensamento e linguagem. São Paulo: Martins fontes, 2008.
Recebido em:21 maio 2014. Aceito em: 25 jun. 2014. 